\title{
Communication \\ Using Age-0 Stocking to Assess Growth and Recruitment of Endangered Pallid Sturgeon Scaphirhynchus albus
}

\author{
Nathan J. C. Gosch ${ }^{1} *{ }^{\mathbb{D}}$, Todd R. Gemeinhardt ${ }^{1}$, Jerrod R. Hall ${ }^{2}$, Kasey W. Whiteman ${ }^{3}$, Tim L. Welker ${ }^{4}$ \\ and Joseph L. Bonneau 4 \\ 1 U.S. Army Corps of Engineers, Environmental Resources Section, Kansas City, MO 64106, USA; \\ todd.r.gemeinhardt@usace.army.mil \\ 2 Nebraska Game and Parks Commission, Lincoln, NE 68503, USA; jerrod.hall@nebraska.gov \\ 3 Missouri Department of Conservation, St. Joseph, MO 64507, USA; kasey.whiteman@mdc.mo.gov \\ 4 U.S. Army Corps of Engineers, Yankton, SD 57078, USA; tim.l.welker@usace.army.mil (T.L.W.); \\ joseph.l.bonneau@usace.army.mil (J.L.B.) \\ * Correspondence: nathan.j.gosch@usace.army.mil
}

check for updates

Citation: Gosch, N.J.C.; Gemeinhardt, T.R.; Hall, J.R.; Whiteman, K.W.; Welker, T.L.; Bonneau, J.L. Using Age-0 Stocking to Assess Growth and Recruitment of Endangered Pallid Sturgeon Scaphirhynchus albus. Fishes 2022, 7, 50. https://doi.org/ $10.3390 /$ fishes7010050

Academic Editor: Maria

Angeles Esteban

Received: 16 January 2022

Accepted: 14 February 2022

Published: 16 February 2022

Publisher's Note: MDPI stays neutral with regard to jurisdictional claims in published maps and institutional affiliations.

Copyright: (C) 2022 by the authors. Licensee MDPI, Basel, Switzerland. This article is an open access article distributed under the terms and conditions of the Creative Commons Attribution (CC BY) license (https:// creativecommons.org/licenses/by/ $4.0 /)$.

\begin{abstract}
Assessing growth and recruitment can be difficult during early life history, especially for rare species such as the pallid sturgeon Scaphirhynchus albus (federally endangered in the United States). One potential tool to address this knowledge gap is the stocking of age-0 individuals. (2) During July 2018, two stocking events of marked age-0 pallid sturgeon (53-56 or 41-42 days old) occurred in the lower Missouri River resulting in the release of 8495 individuals. Over the following three years, pallid sturgeon were sampled with baited trotlines and benthic trawls during routine monitoring. (3) During this period, we captured 77 individuals that recruited to age 1 or older. Only $9 \%$ of captured individuals yielded length-at-age values falling below the $95 \%$ prediction interval for pallid sturgeon raised entirely in an energetically favorable hatchery environment with abundant food resources. (4) These results suggest that the lower Missouri River is capable of supporting hatchery-level growth for young pallid sturgeon. This study also provided a unique opportunity to document recruitment to age- 1 of age- 0 pallid sturgeon stocked at relatively small sizes, which highlights the potential benefits of utilizing stocking to address endangered species knowledge gaps.
\end{abstract}

Keywords: age-0; endangered; growth; lower Missouri River; pallid sturgeon; Scaphirhynchus albus; survival

\section{Introduction}

Growth is one of the key metrics studied in fish population dynamics because it affects present and future population status [1]. This metric can also provide important information regarding prey availability and habitat quality (i.e., fast growth indicates sufficient prey resources and habitat quality, whereas slow growth may suggest the opposite) [2]. Therefore, having a basic understanding of growth rate for individuals in a study population, and how this metric compares to other populations (e.g., those known to exhibit fast growth), can help guide conservation and management efforts. This information, however, can be challenging to gather for rare species, especially during early life history. For instance, the pallid sturgeon (Scaphirhynchus albus) is a federally endangered species inhabiting the Mississippi and Missouri rivers in the United States [3], and published literature only documents seven wild-produced exogenously feeding age- 0 pallid sturgeon (20-48 $\mathrm{mm}$ in length) that have been genetically confirmed $[4,5]$.

Given the limited information available for pallid sturgeon during early life history, the stocking of age-0 individuals is one potential tool to address this knowledge gap [6]. In the Missouri River, pallid sturgeon propagation began in the early 1990s, resulting in an established, long-term stocking program capable of marking and releasing a wide range of ages [7]. During July of 2018, pallid sturgeon ranging from either 53-56 or 41-42 days old [6] 
were released into the lower Missouri River (LMOR; Gavins Point Dam, South Dakota downstream to the Mississippi River confluence at St. Louis, Missouri) as part of two stockings conducted during consecutive weeks. The subsequent capture of some of these individuals provided the opportunity to learn about a potentially important and difficultto-study life stage for an endangered species in this large river system. Gemeinhardt et al. (2021) [6] documented dispersal distance following these stocking events, but there is also an opportunity to assess growth in this river and to make length-at-age comparisons with individuals raised entirely in Gavins Point National Fish Hatchery (GPNFH; Yankton, South Dakota, USA). Given the energetically favorable rearing conditions coupled with abundant food resources (i.e., all pallid sturgeon were fed until satiation), hatcheries can provide a benchmark for assessing growth. For example, Coho Salmon Oncorhynchus kisutch reared from fry to smolt in a hatchery were significantly longer and heavier than siblings reared in a natural river side-channel [8].

Food limitation is a potential limiting factor for pallid sturgeon recruitment to age 1 in the LMOR (e.g., [9]), but information on prey consumption in this system is limited given the small number of wild pallid sturgeon captures, which have consisted of individuals $<50 \mathrm{~mm}$ long [5]. As such, laboratory work has also been conducted to better understand prey use and growth. For example, Porreca et al. (2017) [10] modeled the growth rate potential of age-0 pallid sturgeon (average size $=161 \mathrm{~mm}$ ) as well as the closely related shovelnose sturgeon (Scaphirhynchus platorynchus, average size $=166 \mathrm{~mm}$ ) to compare the ability of these two congeners to assimilate prey. They reported that pallid sturgeon yielded a lower modeled growth rate potential in most, but not all, of the artificial habitat treatments; however, these treatments may not reflect river conditions and relative differences do not necessarily indicate that pallid sturgeon are unable to grow and survive in the wild. Thus, the purpose of our study is to use field and hatchery data to provide insight regarding growth and potential food limitation for age- 0 pallid sturgeon (stocked at fork lengths ranging from approximately 70 to $135 \mathrm{~mm}$ ) that have spent over $80 \%$ of their life in the LMOR.

\section{Materials and Methods}

Pallid sturgeon propagation involved spawning six wild females and eight wild males (using a total of eight crosses) in May of 2018 at GPNFH [6]. Following hatch, offspring rearing occurred for either 53-56 or 41-42 days in water temperatures of $21.1-22.3{ }^{\circ} \mathrm{C}$ [6]. Stocking occurred during consecutive weeks in July 2018 at river km 1113.7 near Decatur, Nebraska (Figure 1). During the first stocking event 9-12 July, 4861 fish were released at a mean fork length of $118 \mathrm{~mm}$. During the second stocking event on 18-19 July, 3634 individuals were released at a mean fork length of $80 \mathrm{~mm}$. Prior to stocking, hatchery staff marked all individuals with Visual Implant Elastomer (VIE) tags to allow for the quick and reliable detection of post-stocking capture (Figure 2). Additionally, colored VIE tags were used to distinguish between stockings.

Pallid sturgeon were sampled from July 2018 through June 2021 with baited trotlines (set overnight) or otter trawls (either 4-mm or 16-mm mesh) during routine annual sampling efforts. We compared the growth of captured pallid sturgeon to fish reared in GPNFH (length recorded prior to release into the LMOR) during 2002-2018 by constructing lengthat-age scatterplots for individuals captured from both stocking events as well as fish raised at GPNFH. Linear regression with the associated 95\% prediction interval was conducted for GPNFH fish to provide context to the growth of captured individuals. We also performed linear regression analysis specific to each stocking event and used analysis of covariance (ANCOVA), with age as the covariate, to assess potential differences in slope and y-intercept values among stocking 1 , stocking 2 , and GPNFH. If slope values were significantly different (i.e., not parallel), then y-intercept comparisons were not conducted [11]. Three individuals from the first stocking were removed from the growth analysis, as they had spent little time in the LMOR (13-41 days) prior to capture. 


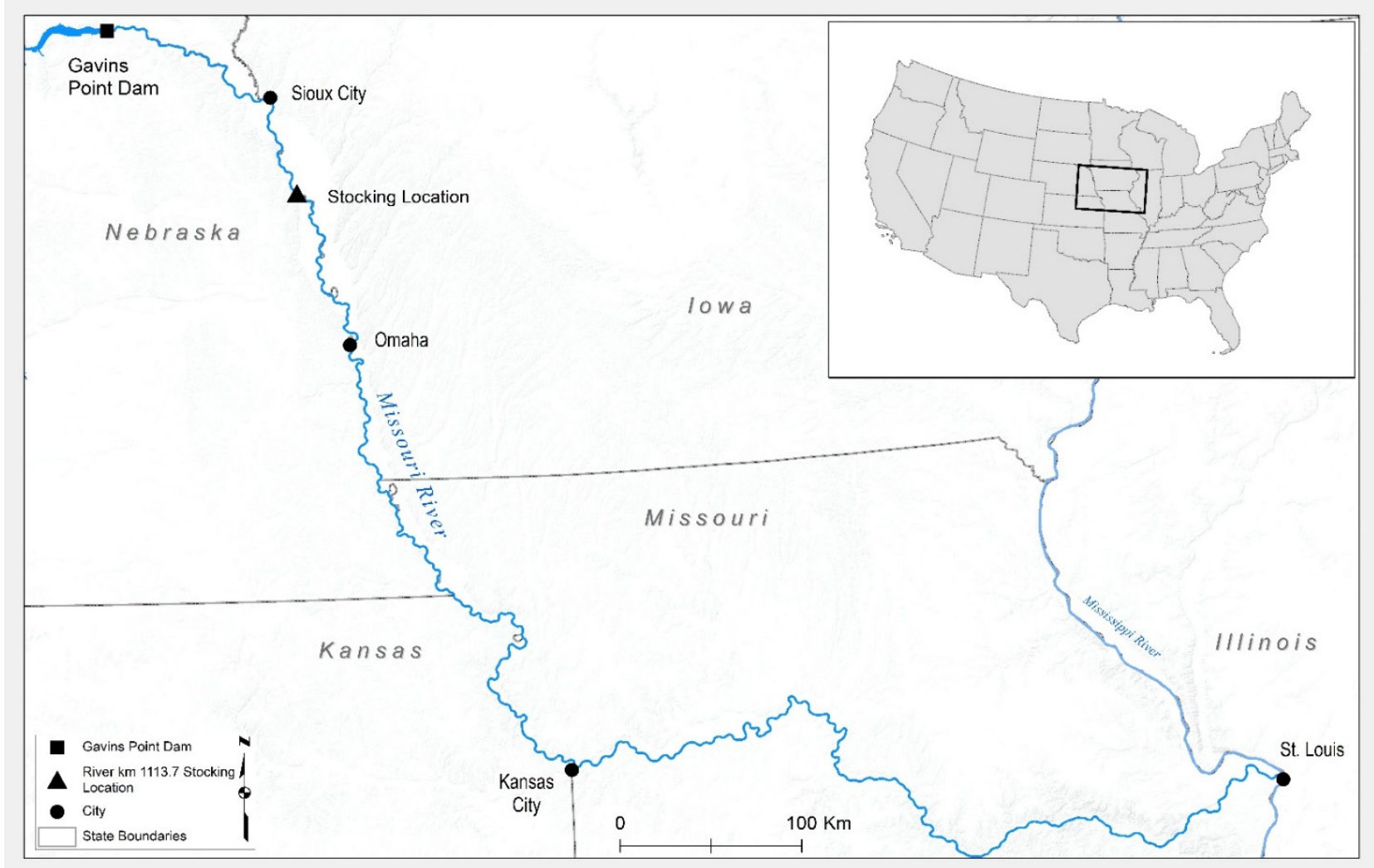

Figure 1. Map of the lower Missouri River, including the age-0 pallid sturgeon stocking location.

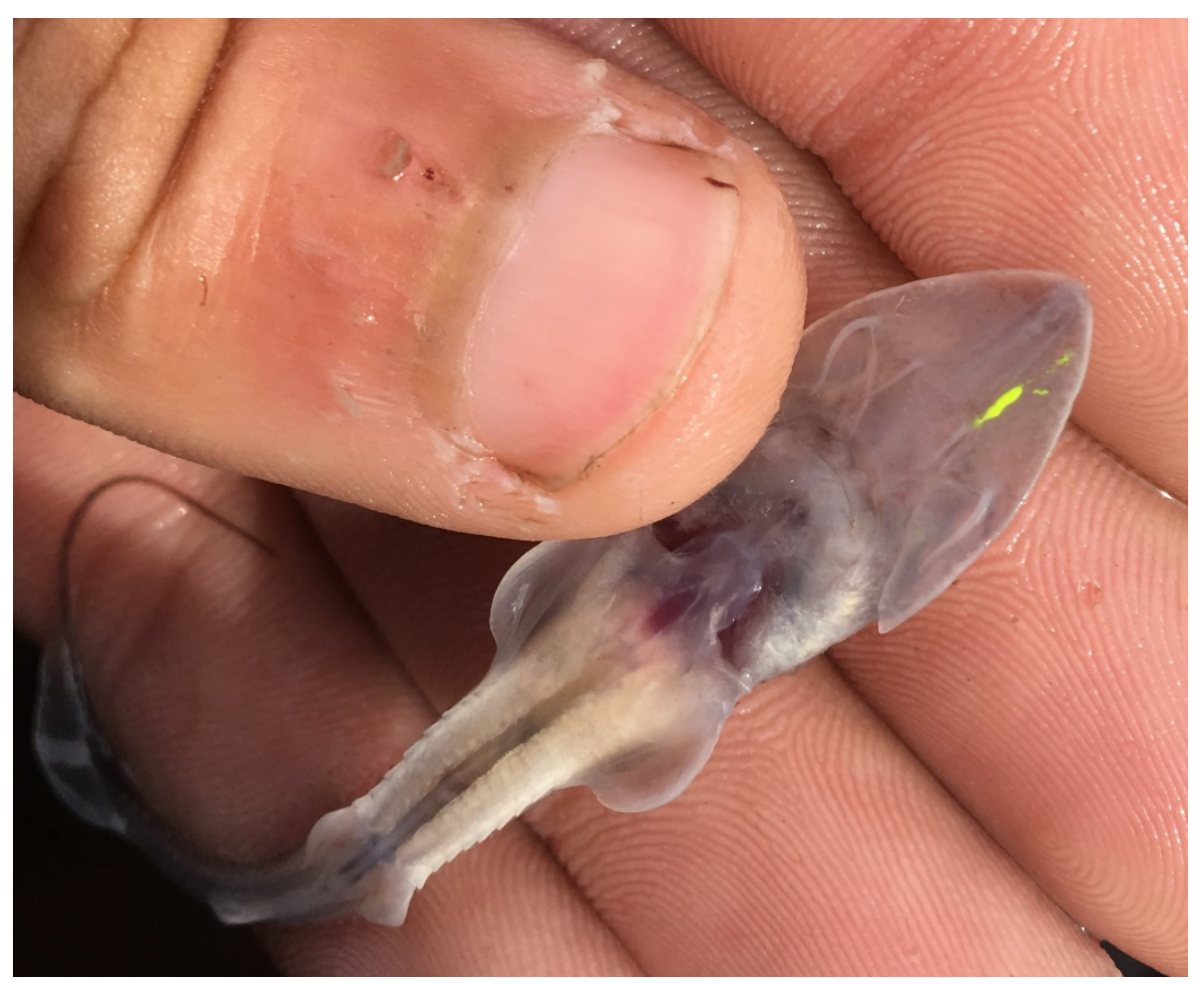

Figure 2. Photo of an age-0 pallid sturgeon stocked during July of 2018 and marked with a Visual Implant Elastomer (vertical yellow line inserted into the rostrum). Photo courtesy of Justin Bounds. 


\section{Results}

Trotlines accounted for $88 \%$ of captures during this study, while otter trawls accounted for the remaining $12 \%$. We documented 77 stocked pallid sturgeon that recruited to age- 1 and older (38 from stocking 1 and 39 from stocking 2). These individuals spent a minimum of $83 \%$ of their post-hatch life in the LMOR. The length-at-age linear regressions (Figure 3 ) were significant for stocking $1\left(\mathrm{r}^{2}=0.25, p=0.001, d f=1\right)$, stocking $2\left(\mathrm{r}^{2}=0.32, p<0.001\right.$, $d f=1)$, and GPNFH $\left(\mathrm{r}^{2}=0.58, p<0.001, d f=1\right)$. Over $78 \%$ and $87 \%$ of stocking 1 and stocking 2 captures, respectively, fell within the $95 \%$ prediction interval for fish reared at GPNFH (Figure 3). Only $11 \%$ and $8 \%$ of stocking 1 and 2 captures, respectively, fell below the $95 \%$ prediction interval, while $11 \%$ and $5 \%$ of stocking 1 and 2 captures, respectively, fell above the $95 \%$ prediction interval (Figure 3). Regarding the ANCOVA, stocking 1 and 2 did not have different slope $(F=0.0, p=0.98)$ or $y$-intercept $(F=3.15, p=0.08)$ values, whereas stocking $1(F=11.2, p<0.001)$ and stocking $2(F=12.6, p<0.001)$ both had different slope values compared to GPNFH.

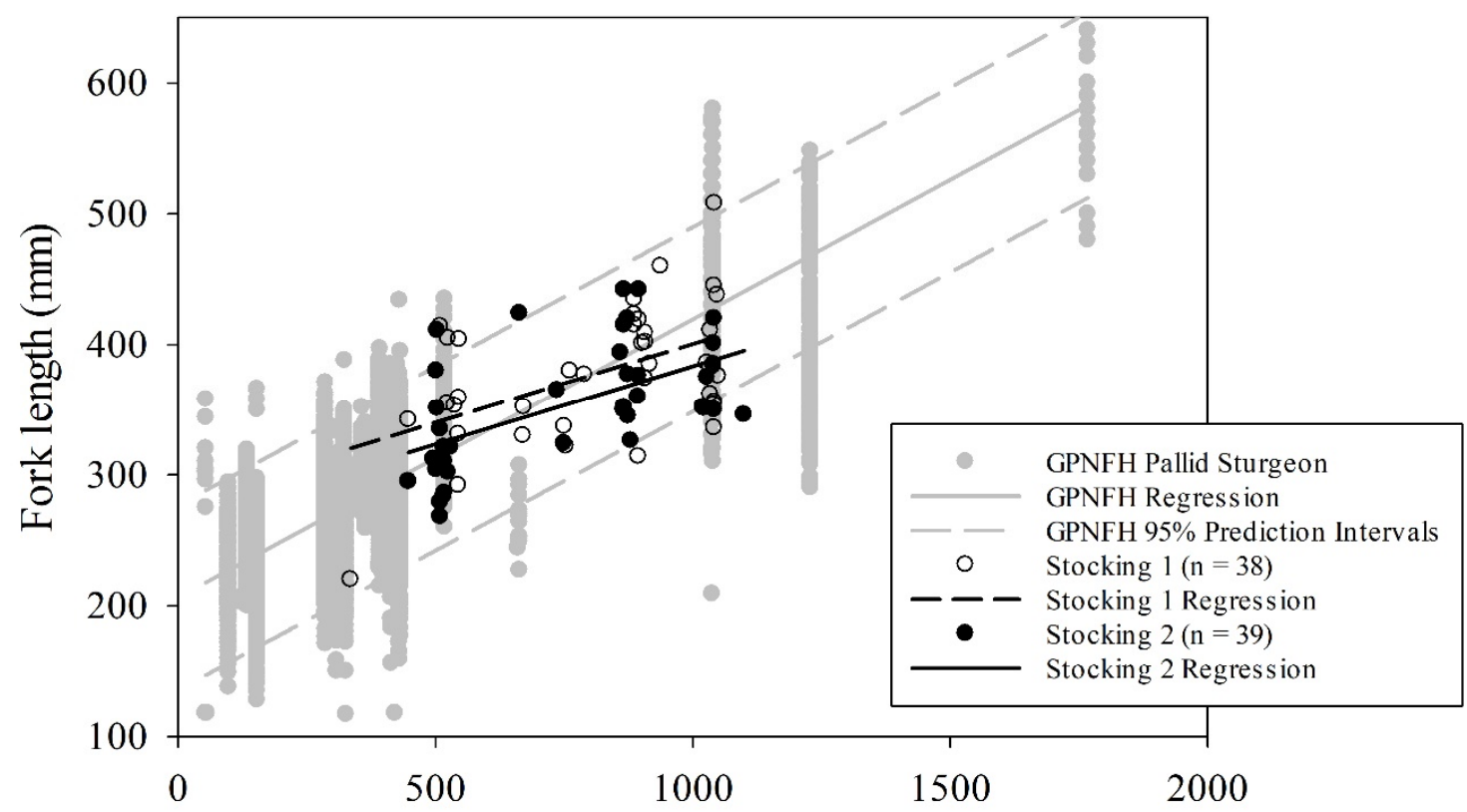

Age (days post hatch)

Figure 3. Scatterplots of pallid sturgeon Scaphirhynchus albus length-at-age data at the time of capture for stocking 1 (9-12 July 2018, mean length at stocking = $118 \mathrm{~mm}$ ) and stocking 2 (18-19 July 2018, mean length at stocking $=80 \mathrm{~mm}$ ) in the lower Missouri River, as well as fish raised at Gavins Point National Fish Hatchery (GPNFH) and stocked into the lower Missouri River from 2002 to 2018.

\section{Discussion}

This study provided a rare opportunity to document the survival of relatively small age- 0 pallid sturgeon stocked into the LMOR and to assess subsequent growth. Many of the hypothesized factors limiting pallid sturgeon population growth involve the age-0 life stage, and one of the main recovery objectives is to increase recruitment to age 1 [9]. However, relatively little information is available for much of this life stage because wild age- 0 pallid sturgeon captures are rare [5], and most age- 0 pallid sturgeon are stocked late in the year at larger sizes and older ages relative to this study. For example, Steffensen et al. (2019) [7] noted that from 1999 to 2015, the average age-0 pallid sturgeon stocked was $231 \mathrm{~mm}$ long and 153 days old. During the present study, we captured $0.94 \%$ of the fish stocked during July of 2018, and our captures confirmed that at least $0.90 \%$ recruited to age 1 or older. Despite the relatively small body size for both stockings during July of 2018, the rate of capture was high relative to most other age- 0 stockings, as Steffensen et al. (2019) [7] reported an average age-0 capture rate of $0.34 \%$. These findings 
may have implications for future decisions regarding age- 0 stocking size, but other factors (e.g., parental crosses, river conditions at the time of release) may have also influenced subsequent survival and capture rates [7].

This study also provided an opportunity to better understand if insufficient prey resources, which is a hypothesized limiting factor for age-0 pallid sturgeon [9], may be affecting growth and survival of these stocked individuals. Porreca et al. (2017) [10] observed subtle physiological differences (e.g., alimentary canal length) between pallid sturgeon (average size $=161 \mathrm{~mm}$ ) and shovelnose sturgeon (average size $=166 \mathrm{~mm}$ ) during a laboratory study. They also modeled growth rate potential for both species hypothesizing that interspecific differences in the ability to metabolize food may account for the difference in survivorship between these species in the wild. However, Gosch et al. (2019) [5] discussed how these laboratory comparisons by Porreca et al. (2017) [10] may not be applicable to sturgeon in the LMOR. For example, the pallid sturgeon growth rate potential was higher than shovelnose sturgeon in the gravel-dominant (mean diameter $=1 \mathrm{~cm}$ ) substrate treatments with approximately $80 \%$ or more gravel [10], and widely available sand dune habitat in the LMOR may also provide important energetic refugia that could benefit pallid sturgeon growth [12]. The individuals captured during the present study allowed us to directly assess pallid sturgeon growth in the wild because fish were stocked at smaller sizes, and subsequently captured at larger sizes, than the individuals studied by Porreca et al. (2017) [10]. Given that individuals were fed until satiation in an energetically favorable environment, we were not surprised that the overall length-at-age trend line for GPNFH was steeper indicating faster growth relative to stocking 1 and 2. However, we did not expect the high degree of overlap among the length-at-age scatterplots with values for stocking 1 and 2 always falling within the range of values observed for GPNFH. We were also surprised that only $9 \%$ of captured fish fell below the $95 \%$ prediction intervals for GPNFH, and that the length-at-age trend lines indicated higher growth for individuals $<800$ days old and $<600$ days old from stocking 1 and stocking 2 , respectively, compared to GPNFH (Figure 3). These unexpected observations may suggest that the ANCOVA results were not biologically significant. Overall, this study demonstrates that the LMOR is capable of yielding hatchery-level growth for young pallid sturgeon, which is inconsistent with the Porreca et al. (2017) [10] hypothesis that pallid sturgeon are endangered due to a relatively limited ability to assimilate prey in the contemporary LMOR.

One potential explanation for the observed growth is that extensive flooding during 2019 provided increased prey resources in the LMOR. However, Gosch et al. (2021) [13] documented that age-0 Scaphirhynchus sturgeon $(\leq 120 \mathrm{~mm})$ captured from floodplain and mainstem habitats in 2019 did not have increased condition (based on length-weight relationships) compared to other years. Additionally, condition declined for many juvenile pallid sturgeon ( 400 to $699 \mathrm{~mm}$ ) following the 2011 LMOR flood [14]. Previous research has also suggested that wild age- 0 pallid sturgeon consume similar prey in similar amounts as the abundant shovelnose sturgeon $[4,5]$, and that natural reproduction was responsible for an estimated $8 \%$ of pallid sturgeon captures in the LMOR from 2003 to 2015 [15]. Our results, coupled with this prior research, suggest a lack of evidence for the hypothesis that LMOR pallid sturgeon are limited by insufficient prey resources, and we recommend focusing research efforts on other hypothesized limiting factors (e.g., altered drift dynamics) [16]. If future research suggests otherwise, an adaptive management framework is in place to reprioritize prey-related research [5]. Gemeinhardt et al. (2021) [6] demonstrated that artificial stockings can be a valuable tool for understanding the dispersal of young pallid sturgeon, and this study further highlights the potential benefits of endangered species stocking efforts.

Author Contributions: Study design, N.J.C.G., T.R.G. and J.L.B.; data management, N.J.C.G., J.R.H., K.W.W. and T.L.W.; data analysis, N.J.C.G.; writing-manuscript development, N.J.C.G.; writingreview and editing, N.J.C.G., T.R.G., J.R.H., K.W.W., T.L.W. and J.L.B. All authors have read and agreed to the published version of the manuscript. 
Funding: Funding was provided by the U.S. Army Corps of Engineers, Kansas City and Omaha Districts.

Institutional Review Board Statement: The study was conducted with all necessary state and federal permits obtained prior to sampling, and we adhered to federal pallid sturgeon handling protocols [17].

Data Availability Statement: Data are available upon reasonable request.

Acknowledgments: We thank the Nebraska Game and Parks Commission, Missouri Department of Conservation and U.S. Army Corps of Engineers field crews for fish collection. We thank GPNFH for providing length-at-age data. Any use of trade, firm, or product names is for descriptive purposes only and does not imply endorsement by the U.S. Government. All product names and trademarks cited are property of their respective owners. This report is not to be construed as an official Department of Army position unless so designated by other authorized documents.

Conflicts of Interest: The authors declare no conflict of interest.

\section{References}

1. Pope, K.L.; Lochmann, S.E.; Young, M.K. Methods for assessing fish populations. In Inland Fisheries Management in North America, 3rd ed.; Hubert, W.A., Quist, M.C., Eds.; American Fisheries Society: Bethesda, MD, USA, 2010; pp. $325-351$.

2. Allen, M.S.; Hightower, J.E. Fish population dynamics: Mortality, growth, and recruitment. In Inland Fisheries Management in North America, 3rd ed.; Hubert, W.A., Quist, M.C., Eds.; American Fisheries Society: Bethesda, MD, USA, 2010 ; pp. 43-79.

3. U.S. Fish and Wildlife Service. Endangered and threatened wildlife and plants: Determination of endangered status for the pallid sturgeon. Fed. Regist. 1990, 55, 36641-36647.

4. Gosch, N.J.C.; Civiello, A.P.; Gemeinhardt, T.R.; Bonneau, J.L.; Long, J.M. Are shovelnose sturgeon a valid diet surrogate for endangered pallid sturgeon during the first year of life? J. Appl. Ichthyol. 2018, 34, 39-41. [CrossRef]

5. Gosch, N.J.C.; Gemeinhardt, T.R.; Civiello, A.P.; Harrison, A.B.; Bonneau, J.L. Dietary assessment of age-0 pallid sturgeon and shovelnose sturgeon: Implications for surrogacy. Endanger. Species Res. 2019, 40, 321-327. [CrossRef]

6. Gemeinhardt, T.R.; Gosch, N.J.C.; Hall, J.R.; Whiteman, K.W.; Welker, T.L.; Bonneau, J.L. Assessing large-scale movement of an endangered fish: Dispersal of stocked age-0 pallid sturgeon in the lower Missouri River. Aquat. Conserv. Mar. Freshw. Ecosyst. 2021, 31, 3326-3333. [CrossRef]

7. Steffensen, K.D.; Hamel, M.J.; Spurgeon, J.J. Post-stocking pallid sturgeon Scaphirhynchus albus growth, dispersal, and survival in the lower Missouri River. J. Appl. Ichthyol. 2019, 35, 117-127. [CrossRef]

8. Chittenden, C.M.; Biagi, C.A.; Davidsen, J.G.; Davidsen, A.G.; Kondo, H.; McKnight, A.; Pedersen, O.P.; Raven, P.A.; Rikardsen, A.H.; Shrimpton, J.M.; et al. Genetic versus rearing-environment effects on phenotype: Hatchery and natural rearing effects on hatchery- and wild-born coho salmon. PLoS ONE 2010, 5, e12261. [CrossRef] [PubMed]

9. Jacobson, R.B.; Annis, M.L.; Colvin, M.E.; James, D.A.; Welker, T.L.; Parsley, M.J. Missouri River Scaphirhynchus Albus (Pallid Sturgeon) Effects Analysis_Integrative Report 2016; U.S. Geological Survey Scientific Investigations Report 2016-5064: Reston, VA, USA, 2016. [CrossRef]

10. Porreca, A.P.; Hintz, W.D.; Coulter, D.P.; Garvey, J.E. Subtle physiological and morphological differences explain ecological success of sympatric congeners. Ecosphere 2017, 8, e01988. [CrossRef]

11. Pope, K.L.; Kruse, C.G. Condition. In Analysis and Interpretation of Freshwater Fisheries Data; Guy, C.S., Brown, M.L., Eds.; American Fisheries Society: Bethesda, MD, USA, 2007; pp. 423-471.

12. Porreca, A.P.; Hintz, W.D.; Garvey, J.E. Do alluvial sand dunes create energetic refugia for benthic fishes? An experimental test with the endangered pallid sturgeon. River Res. Appl. 2017, 33, 690-696. [CrossRef]

13. Gosch, N.J.C.; Hall, J.R.; Civiello, A.P.; Haas, J.D.; Gemeinhardt, T.R.; Bonneau, J.L. Floodplain connectivity and age-0 sturgeon prey consumption in the lower Missouri River. River Res. Appl. 2021, 37, 1243-1253. [CrossRef]

14. Steffensen, K.D.; Mestl, G.E.; Phelps, Q.E. Range-wide assessment of pallid sturgeon Scaphirhynchus albus (Forbes \& Richardson, 1905) relative condition. J. Appl. Ichthyol. 2017, 33, 13-21. [CrossRef]

15. Steffensen, K.D., Chojnacki, K.A.; Kalie, J.A.; Bartron, M.L.; Heist, E.J.; Winders, K.R.; Loecker, N.C.; Doyle, W.J.; Welker, T.L. Evidence of limited recruitment of pallid sturgeon in the lower Missouri River. J. Fish Wildl. Manag. 2019, 10, 336-345. [CrossRef]

16. Civiello, A.P.; Gosch, N.J.C.; Gemeinhardt, T.R.; Miller, M.L.; Bonneau, J.L.; Chojnacki, K.A.; DeLonay, A.J.; Long, J.M. Diet and condition of age-0 Scaphirhynchus sturgeon: Implications for shallow-water habitat restoration. N. Am. J. Fish. Manag. 2018, 38, 1324-1338. [CrossRef]

17. U.S. Fish and Wildlife Service. Biological Procedures and Protocols for Researchers and Managers Handling Pallid Sturgeon; U.S. Fish and Wildlife Service: Billings, MT, USA, 2012. 